\title{
Assessment of a simple scoring system applied to a screening questionnaire for asthma in children aged 5-15 yrs
}

\author{
T.L. Frank*, P.I. Frank*, R. McNamee**, T. Wright, P. Hannaford***, J. Morrison ${ }^{+}$, \\ S. Hirsch*, C.A.C. Pickering*
}

Assessment of a simple scoring system applied to a screening questionnaire for asthma in children aged 5-15 yrs. T.L. Frank, P.I. Frank, R. McNamee, T. Wright, P. Hannaford, J. Morrison, S. Hirsch, C.A.C. Pickering. (C)ERS Journals Ltd 1999.

ABSTRACT: The aim of the present study was to validate a simple scoring system using a parent-completed screening questionnaire to identify children aged 5-15 yrs who may have asthma.

A stratified random sample of 157 children of 1,808 whose parents had answered a postal respiratory questionnaire underwent detailed clinical evaluation. The results were reviewed by three independent paediatricians whose opinions were combined to reach, for each child, decisions regarding three standards: 1) "possible asthma" defined as $>\mathbf{5 0} \%$ likelihood of having asthma; 2) "possible asthma" defined as meriting a clinical trial of asthma medication; and 3) "probable asthma" defined as $>90 \%$ likelihood of having asthma. The combined decisions were compared to three sets of questionnaire scores, in order to determine the positive predictive value, sensitivity and specificity of each set in identifying children with probable/possible asthma.

The three sets of chosen questionnaire scores all had positive predictive values of $79-96 \%$ for predicting possible asthma, using either the combined expert opinion " $>\mathbf{5 0} \%$ likelihood of asthma" or that of "warrants a trial of treatment" as the definition. This suggests that a low proportion of false positives would be obtained were this scoring system to be used for a screening programme. The combined decision $>\mathbf{9 0} \%$ chance of asthma could be used as a means of estimating prevalence of asthma in the survey. When used for this, the prevalence of asthma in the surveyed population was $18.8 \%$ (95\% confidence interval 13.1-26.3).

In conclusion, the present scoring system, based on a simple respiratory questionnaire, provides a valid method of identifying children likely to have asthma, and who, if unknown to the medical services, would benefit from clinical review. Eur Respir J 1999; 14: 1190-1197.

\begin{abstract}
*North West Lung Research Centre, Wythenshawe Hospital, Manchester, ** Centre for Occupational Health School of Epidemiology and Health Sciences University of Manchester ***R.C.G.P. Centre for Primary Care Research \& Epidemiology, University of Aberdeen ${ }^{+}$Molecular Medicine Unit, St James University Hospital, Leeds
\end{abstract}

Correspondence: T. Frank, North West Lung Research Centre, Wythenshawe Hospital, Southmoor Rd, Manchester M23 9LT, UK. Fax: 441612915047

Keywords: Asthma

children

screening

validation

Received: November 31998

Accepted after revision June 201999

This study was supported by Glaxo-Wellcome, Zeneca Pharmaceuticals, Manchester Airport, the Royal College of General Practitioners and the North West Lung Centre.
It has been reported that asthma is underdiagnosed and undertreated [1-7]. In the short term, this probably leads to increased morbidity for sufferers, and, in the long-term, it may have a detrimental effect on their lung function and clinical state [8]. It has been suggested that failure to treat airway inflammation may cause airway remodelling $[9$, 10]. If so, there may be clinical benefits to the individual and health economic benefits to society from identifying and treating patients who have asthma but who are unknown to the medical services. Before this hypothesis can be tested, mechanisms for identifying and quantifying such patients need to be established. Full clinical review of everyone in a community is not a cost-effective or practical option. A more practical alternative might be the use of a screening questionnaire, designed to identify individuals most likely to have the condition, and therefore most likely to benefit from clinical review.

The Wythenshawe Community Asthma Project, is a long-term prospective study of the natural history of asth$\mathrm{ma}$ in two general practice populations in Manchester, UK. One of its aims is to develop a method of identifying patients in the community with asthma as the first stage of evaluating the value and costs of treating such indivi- duals. In 1993 and 1995, postal respiratory questionnaire surveys were carried out in both practice populations. In order to identify patients who may have asthma, a simple scoring system was used based on the number of positive responses to key questions. Questionnaire responses were linked to practice records in order to determine those patients who, on the basis of their questionnaire responses, may be asthmatic but whose records contained no diagnosis of asthma nor provision of asthma medication during the previous year. Using this methodology, it was estimated that up to $10 \%$ of children in the populations may have had asthma which was unknown to the medical services [11]. This paper examines the validity of this scoring system in children aged 5-15 yrs, using data relating to respondents to the 1995 postal survey.

The aim thus was to asses a simple scoring system for a screening questionnaire for asthma in 5-15-yr-old children against three standards: 1) "possible asthma" defined as a consensus expert opinion of $>50 \%$ likelihood of having asthma; 2) "possible asthma" defined as a consensus expert opinion of meriting a clinical trial of asthma medication; and 3) "probable asthma" defined as a consensus expert opinion of $>90 \%$ likelihood of such a diagnosis. 


\section{Methods}

In September 1995, postal questionnaires (appendix 1) were sent to the parents/guardians of all children registered with two practices in South Manchester. Reminders were sent to nonrespondents 4 and 8 weeks after the initial posting. The questionnaire was based on that used in the International Study of Asthma and Allergies in Childhood (ISAAC) [12]. In addition, the questionnaire asked whether the child had received more than three courses of antibiotics for respiratory symptoms in the previous year, a circumstance often regarded as the first indication of asthma in young children and used as a key item in a previous study [13]. Additional questions asked about a history of hay fever or eczema, a family history of asthma and the number of smokers in the household.

\section{Sample stratification}

From the respondents, a stratified random sample of children aged 5-15 yrs was selected to undergo full clinical examination at the North West Lung Research Centre, Wythenshawe Hospital, Manchester. In order to determine which sample to use, children were first stratified according to the number of positive responses to questions on the following five key subjects: 1) wheezed in the last 12 months; 2) woken at night by cough in the absence of a cold or respiratory infection in the last 12 months; 3 ) received more than three courses of antibiotics for respiratory symptoms (both upper and lower respiratory tract) in the last 12 months; 4) history of hay fever or eczema; and 5) family history of asthma in first degree relatives.

From each stratum, random samples were taken (with strata relating to one or two positive responses aggregated for sampling purposes). The sampling fraction for each stratum was chosen in advance in order to give approximately equal numbers of asthmatics and nonasthmatics in the overall sample (using estimates of the expected prevalence of asthma in each stratum). The number from each stratum invited to and the number attending the clinical review are shown in table 1 . The invitation process involved the children's general practitioners contacting their parents by telephone or home visit to offer clinical review at the local hospital.

\section{Clinical assessment}

The clinical assessment involved taking a full medical history, physical examination and investigations. The content of the clinical assessment was developed using the

Table 1. - Number of respondents, children invited for clinical review and finally attending for review by number of positive responses reported in the postal survey

\begin{tabular}{lcccccc}
\hline & \multicolumn{7}{c}{ Number of positive responses } \\
\cline { 2 - 7 } & 0 & 1 or 2 & 3 & 4 & 5 & Total \\
\hline $\begin{array}{l}\text { All respondents n } \\
\begin{array}{l}\text { Children invited for } \\
\text { for clinical review nn }\end{array}\end{array}$ & 491 & 939 & 206 & 140 & 32 & 1808 \\
$\begin{array}{l}\text { Children attending for } \\
\text { clinical review n (\% } \\
\text { of those invited) }\end{array}$ & 22 & 34 & 72 & 62 & 13 & 228 \\
\hline
\end{tabular}

Delphi Technique [14] to obtain a consensus opinion from 24 paediatricians with a special interest in chest medicine. The paediatricians were asked to detail what clinical information they felt was needed by a physician to enable them to decide on the likelihood of a child having asthma. Details of this exercise will be reported elsewhere. The content of the clinical assessment is shown in appendix 2 .

Spirometry was performed according to guidelines defined by the American Thoracic Society Snowbird Workshop [15] using a Morgan Spiroflow rolling dry-seal spirometer (PK Morgan, Gillingham, Kent, UK) connected to an Apple Macintosh computer (Apple Computers, Cupertino, CA, USA) running Macspiro software (Macspiro Software, Leicestershire, UK). Forced expiratory volume in one second (FEV1), forced vital capacity (FVC), and FEV1/FVC ratio were measured.

Reversibility testing to $\beta_{2}$-agonists was performed [16]; a positive result was defined as an increase in the FEV 1 of $>15 \%$ from the prebronchodilator spirometry value 20 min after administration of $200 \mu \mathrm{g}$ salbutamol through a large-volume spacer device.

A free running exercise challenge test was also performed [17]. This consisted of the children running outdoors for $6 \mathrm{~min}$ at their maximum capacity, which was ensured by encouragement from the investigators. Spirometry was performed at 2, 3, 5, 10, 15 and 20 min after exercise. A positive exercise test was defined by a fall in FEV1 of $20 \%$ at any of these time points.

A peak flow diary was collected using a Vitalograph model 2110 (Vitalograph, Buckinghamshire, UK). The machine was individually set up for each child and the child shown how to use the device under supervision until they were able to perform adequate reproducible blows. The machine was programmed to bleep at a prearranged time between 06:00 and 09:00 h for each child and again $12 \mathrm{~h}$ later. The machine switched itself off after two reproducible blows had been obtained. It measures FEV1 and peak expiratory flow rate.

Skin-prick testing using the skin-prick/puncture technique [18] was performed using Hollister-Stier prick lancets and skin test solutions (Hollister-Stier Laboratories, Spokane, WA, USA). Tests were performed with positive (histamine $10 \mathrm{mg} \cdot \mathrm{mL}^{-1}$ ) and negative (glycennated extract) controls as well as house dust mite, grass pollen, cockroach, dog and cat allergens. Atopy was defined by a skin weal $3 \mathrm{~mm}$ in diameter greater than that of the negative control.

The clinical history taking and examination were carried out by a clinician (T.L. Frank) and investigations performed by a research assistant (T. Wright) supervised and assisted by T.L. Frank. Neither individual had access to the postal questionnaire results for the child being examined.

For each child, three independent consultant paediatricians with a special interest in asthma were sent full details of the clinical assessment in a set format (appendix 2 ). Details of the postal questionnaire result were not sent. On the basis of the clinical assessment information, the paediatricians were asked to first rate each child into one of four categories $(>90 \%, 50-90 \%, 10-50 \%$ or $<10 \%)$ according to their likelihood of having asthma. (The categories were chosen in order to try and determine in a semiquantitative way how strongly the paediatricians felt that a child did or did not have asthma). In addition, the paediatricians were asked to decide whether the child 
merited a trial of asthma medication. (This decision captured the situation sometimes faced in clinical practice when a trial of treatment is given even though a diagnostic label of asthma may not be applied).

Wherever possible, a consensus opinion was used to place the child into a "final diagnostic category". In those instances in which all three specialists gave different opinions, the final category taken was that which corresponded to the middle opinion (table 2). The consultants did not discuss any of the cases between themselves nor was any suggestion made to them as to the relative importance of any feature of the clinical assessment.

The scoring system was compared using three levels of consensus opinion (or "standards"): $>50 \%$ likelihood of the child having asthma; trial of medication warranted; and $>90 \%$ likelihood of asthma. Arguably, the first two standards suggest possible asthma. Evaluating the scoring system against these standards would demonstrate its usefulness in clinical practice, in which clinicians would use the screening questionnaire and scoring system to identify children with possible asthma requiring further detailed assessment to confirm or refute the diagnosis of asthma. Arguably, the third standard suggests probable asthma. Assessing the scoring system against this standard would demonstrate its value in estimating the prevalence of asthma in the community.

The consensus "standards" were compared with three sets of questionnaire scores, chosen in advance on the basis of clinical experience to be probable predictors of asthma. 1) three or more positive responses to the five key questions; 2) Four or more positive responses to the five key questions; 3) Three or more positive responses to the key questions plus at least one of the following markers of severity: 1) exercise-induced wheeze; 2) wheeze affecting speech; 3) more than four attacks of wheeze in the last year; and 4) woken at least weekly by wheeze.

\section{Statistical analysis}

The positive predictive value, sensitivity and specificity were calculated for each score in order to identify children with possible and probable asthma. Because of the stratified random sampling, the usual formulae for calculating sensitivity, specificity and predictive value could not be used. The formulae used are given in appendix 3. Using this method, the results for each stratum were given weights which reflected the size of each stratum in the entire study population $(1,808$ children) rather than in the final sample
(157 children) undergoing detailed examination. Confidence intervals for the prevalence and positive predictive values were calculated using the STATA procedure logit [19], which can incorporate weights and provide robust standard errors. Confidence intervals for sensitivity and specificity were calculated by means of the bootstrap method [20] with bootstrapping carried out separately for each strata.

\section{Results}

Of 2,657 questionnaires sent out in $1995,1,869$ were returned after three postings. After a 5.5\% adjustment for children no longer at the postal address [21], this represented a $75 \%$ response rate. Of these, $1,808(97 \%)$ contained sufficient information for the present analyses; 228 children were invited for clinical review, of whom 157 (69\%) attended.

The agreement between the consultants about the likelihood of asthma diagnosis and whether the child merited a trial of medication is detailed in table 2 . All three consultants agreed on the likelihood of asthma in $96(61 \%)$ children and two of the three agreed in a further $35(22 \%)$ children. Where all disagreed (26 subjects) $(17 \%)$, the final diagnostic category was taken as the middle opinion of the three. There was unanimous agreement concerning the merits of a trial of treatment in $112(70 \%)$ children.

Table 3 compares the consensus expert opinions against the three sets of questionnaire score. Of 101 children with three or more positive responses, $81(80 \%)$ had a $>50 \%$ likelihood of asthma, $87(86 \%)$ merited a trial of medication and $65(64 \%)$ had a $>90 \%$ likelihood of asthma. For the 58 children with four or more positive responses, the results were $50(86 \%), 55(95 \%)$ and $41(71 \%)$ respectively. The results for the 75 children with three or more positive responses plus a marker of severity were 68 $(91 \%), 72(96 \%)$ and $57(76 \%)$ respectively.

The positive predictive value (PPV), sensitivity and specificity of the three scores are shown in table 4 . The PPV of three or more positive responses was $79 \%$ (95\% confidence interval (CI) 69-86) when compared against the consensus opinion ">50\% likelihood of asthma", $84 \%$ (95\% CI 74-90) when compared with "merits a trial of treatment" and 63\% (95\% CI 53-72) when compared with ">90\% likelihood of asthma". For the set of questionnaire scores of four or more positive responses, the corresponding figures were $87 \%$ (95\% CI 75-93), 95\% (95\% CI 86-98) and 71\% (95\% CI 58-82) respectively,

Table 2. - Number of children categorized according to the likelihood of asthma diagnosis and whether meriting a trial of treatment by level of consultant agreement

\begin{tabular}{|c|c|c|c|c|c|c|c|c|}
\hline & \multicolumn{5}{|c|}{ Likelihood of asthma diagnosis } & \multicolumn{3}{|c|}{ Meriting a trial of medication } \\
\hline & $>90 \%$ & $50-90 \%$ & $10-50 \%$ & $<10 \%$ & Total & Yes & No & Total \\
\hline \multicolumn{9}{|l|}{ Consultant agreement } \\
\hline All agreed & 59 & 0 & 1 & 36 & 96 & 70 & 42 & 112 \\
\hline 2 out of 3 agreed & 10 & 4 & 6 & 15 & 35 & $33^{*}$ & $11 * *$ & 44 \\
\hline Consensus where all 3 disagreed & 0 & $16^{* * *}$ & $10^{+}$ & 0 & 26 & 0 & $1^{++}$ & 1 \\
\hline Final categorization & 69 & 20 & 17 & 51 & 157 & 103 & 54 & 157 \\
\hline
\end{tabular}

*: the third consultant made no decision on eight of these children; **: the third consultant made no decision on three of these children; $* * *$ : one consultant chose $>90 \%$, one $50-90 \%$ and the third either $10-50 \%$ or $<10 \% ;^{+}$: one consultant chose $<10 \%$, one $10-50 \%$ and the third either $50-90 \%$ or $>90 \% ;{ }^{++}$: in one case, two consultants disagreed and the third made no decision on treatment, but decided that the child had a $<10 \%$ chance of asthma. It was therefore assumed that the treatment option for this child would have been no treatment. 
Table 3. - Comparison between consensus expert opinions and different sets of questionnaire score

\begin{tabular}{|c|c|c|c|c|}
\hline \multirow[b]{2}{*}{$\begin{array}{l}\text { Questionnaire } \\
\text { score }\end{array}$} & \multicolumn{3}{|c|}{ Consensus opinion } & \multirow[b]{2}{*}{$\begin{array}{l}\text { Total } \\
\text { n }(\%)^{\#}\end{array}$} \\
\hline & $\begin{array}{l}>50 \% \text { likelihood of } \\
\text { asthma } n(\%)\end{array}$ & $\begin{array}{l}\text { Meriting a trial of } \\
\text { medication } \mathrm{n}(\%)\end{array}$ & $\begin{array}{l}>90 \% \text { likelihood of } \\
\text { asthma n (\%) }\end{array}$ & \\
\hline All responses & $89(57)$ & $103(66)$ & $69(44)$ & $157(100)$ \\
\hline 3 positive responses* & $81(80)$ & $87(86)$ & $65(64)$ & $101(100)$ \\
\hline$<3$ positive responses* & $8(14)$ & $16(18)$ & $4(7)$ & $56(100)$ \\
\hline$\geq 4$ positive responses $^{+}$ & $50(86)$ & $55(95)$ & $41(71)$ & $58(100)$ \\
\hline$<4$ positive responses ${ }^{+}$ & 39 (39) & $48(48)$ & $28(28)$ & $99(100)$ \\
\hline$\geq 3$ positive responses & & & & \\
\hline plus one marker of severity & $68(91)$ & $72(96)$ & $57(76)$ & $75(100)$ \\
\hline Other responses & $21(26)$ & $31(38)$ & $12(15)$ & $82(100)$ \\
\hline
\end{tabular}

\#: each of the three "Consensus opinions" is an individual proportion of this total; ${ }^{*},{ }^{+}$, : each pair is taken from "All responses" for each "Consensus opinion".

and, for the set of three or more positive responses plus a marker of severity, 91\% (95\% CI 82-96), 96\% (95\% CI 88-99) and 75\% (CI 64-84\%) respectively.

The prevalence of asthma in the present survey could be calculated by using the formula in appendix 3 . Therefore, using the consensus expert opinion category of $>90 \%$ chance of asthma, the prevalence of probable asthma was estimated to be $18.8 \%$ (95\% CI 13.1-26.3). The estimated prevalence of possible asthma was $28.4 \%$ (95\% CI $20.7-$ 37.7 ) when a definition of $>50 \%$ chance of asthma was used and $41 \%$ (95\% CI 31.3-51.5) when a definition of merits a trial of asthma treatment was used.

\section{Discussion}

A simple scoring system, based on the number of positive responses to key questions in a respiratory questionnaire, when compared with the consensus opinion of three paediatricians, produced high PPVs when using two definitions for possible asthma: $>50 \%$ likelihood of asthma or merits a trial of medication. Lower PPVs were obtained when probable asthma (consensus opinion: $>90 \%$ likelihood of asthma) was used. Conversely, the probable asthma definition gave higher sensitivity values.

Two important sources of selection bias could have occurred. First, nonrespondents to the questionnaire survey could have been materially different from respondents. This was examined after the first questionnaire survey in 1993, when a comparison was made between the practice medical records of a random sample of 100 respondents and 100 nonrespondents. No important differences were found with respect to age, sex, total number of consultations, and consultations for respiratory problems in the previous year. There is no reason to suspect that the situ- ation was different in the 1995 survey. Secondly, the children attending for clinical review may have been different from those who were invited but who did not attend. Evaluation of practice clinical records found no important differences between the 157 children who underwent clinical review and the 65 who were invited but who did not attend the examination with respect to age, sex, total number of consultations in the previous year and consultations for respiratory problems also in the previous year.

The purpose of a screening test is to identify individuals with a high chance of having disease and who require further clinical assessment to confirm or refute the diagnosis. When defining the cut-off point at which results from a screening test are deemed to be positive or negative, consideration has to be taken of the balance between false positive results (which can lead to extra distress because of unnecessary further investigations) and false negative results (which result in some cases of disease being missed). The PPV of a test reflects the frequency of disease in the population screened. The cost-effectiveness of a screening programme will depend on the cut-off values chosen as these determine the number of new cases detected and requiring treatment, unnecessary investigations undertaken, etc.

When assessing a screening test, it is difficult to know what diagnostic standard to use. This is particularly so for a condition such as asthma for which there is no widely accepted clinical definition. In the present study, two definitions for possible asthma were used, based on the consensus opinion of three paediatricians, with an interest in respiratory medicine. The first used a consensus opinion that the child was considered to have a $>50 \%$ likelihood of asthma and the second used a consensus opinion that the child merited a trial of treatment. Many clinicians would

Table 4. - Positive predictive value (PPV), sensitivity (Sens) and specificity (Spec) of the three sets of questionnaire score compared with the three standards based on the consensus opinion

\begin{tabular}{|c|c|c|c|c|c|c|c|c|c|}
\hline \multirow[b]{3}{*}{ Questionnaire score } & \multicolumn{9}{|c|}{ Consensus opinion } \\
\hline & \multicolumn{3}{|c|}{$>50 \%$ likelihood of asthma } & \multicolumn{3}{|c|}{ Meriting a trial of medication } & \multicolumn{3}{|c|}{$>90 \%$ likelihood of asthma } \\
\hline & PPV & Sens & Spec & PPV & Sens & Spec & PPV & Sens & Spec \\
\hline$\geq 3$ positive responses & $79(69-86)$ & $59(45-78)$ & $94(91-96)$ & $84(74-90)$ & $44(33-55)$ & $94(91-97)$ & $63(53-72)$ & $70(50-90)$ & $91(88-93)$ \\
\hline $\begin{array}{l}\geq 4 \text { positive responses } \\
\geq 3 \text { positive responses }+\end{array}$ & $87(75-93)$ & $30(22-39)$ & $98(96-99)$ & $95(86-98)$ & $23(17-29)$ & $99(98-100)$ & $71(58-82)$ & $36(26-49)$ & $97(95-98)$ \\
\hline one marker of severity & $91(82-96)$ & $49(38-65)$ & $98(96-99)$ & $96(88-99)$ & $36(28-45)$ & $99(97-100)$ & $75(64-84)$ & $61(44-80)$ & $95(93-97)$ \\
\hline
\end{tabular}

Data are presented as percentages with $95 \%$ confidence intervals in parentheses. 
probably agree that it is reasonable to assess children with a $>50 \%$ chance of asthma or meriting a trial of asthma treatment in expert opinion. Hence the use of these definitions as standards in the present comparisons. Comparing the different sets of questionnaire scores against each consensus opinion ("standard"), it was possible to determine the test characteristics (sensitivity, specificity and PPV) of each set. The more stringent sets (four or more positive responses to key questions and three or more positive responses to key questions plus a marker of severity) had higher PPVs and greater specificity (and so gave fewer false positive results) than scores with a lower number of responses to key questions, but at the cost of reducing the sensitivity (meaning that more cases were missed). Some clinicians may require a more robust standard for the comparisons. The authors believe that a consensus opinion of $>90 \%$ likelihood of asthma provides this and have compared the findings for the sets of questionnaire score against this standard. In this comparison, the sensitivity of the scoring system increases (i.e. fewer cases are missed) with a marginal drop in specificity (i.e. there are more false positives).

The three specialists reviewing the clinical information relied on detailed written data supplied to them by the research team; they did not have direct contact with either the child or the parent. However, neither the experts nor the examining team were aware of the results of the child's postal questionnaire at the time of their involvement. It was reassuring that a majority verdict concerning the likelihood of diagnosis could be reached in $83 \%$ of children. The difference of opinion in the remainder is a reflection of the problems in diagnosing a condition which has no universally accepted definition. Difficulties in making a diagnosis without personally seeing the patient may also have contributed to the disagreement, although it is likely that some difference of opinion would have persisted even with personal examination. Expert opinion concerning asthma diagnosis has been used to define asthma in previous epidemiological studies $[1,22,23]$, whereas others have used patient recall of asthma diagnosis or treatment in measuring prevalence or underdiagnosis [6].

An advantage of the set of scores chosen in advance on the basis of clinical experience is their simplicity. Techniques such as discriminant analysis and logistic regression could have been used to give each question different weightings. A different scoring system could then have been developed. This would have the disadvantage that validation then would be based on the same data as that used to derive the scoring system and therefore would tend to be over optimistic.

In clinical practice, a simple scoring system for identifying patients requiring further review is attractive. The choice of which set of questionnaire score to use will depend on a number of factors, the balance between the PPV and sensitivity of each category and the availability of healthcare resources. It is important to remember that if this questionnaire were to be used in another setting the PPV would have to be recalculated as it is dependent on the prevalence of disease in the population studied.

In a recent national study [6], one-third of children aged 12-14 yrs reported wheeze in the last 12 months, of whom half had no knowledge of asthma diagnosis or treatment. In another study, wheeze in the last 12 months as a single questionnaire response gave a PPV of only $61 \%$ in diagnosing asthma in children versus physician diagnosis [22]. The relatively high number of children who would need clinical assessment and the high proportion of false positives would make this single symptom unsuitable for use as a screening procedure for identifying unknown asthmatics. A further disadvantage would be that asthma may present with cough in the absence of wheeze [24-26]. By using a combination of different features of asthma, the present scoring systems, which included both wheeze and cough, achieved considerably improved PPVs. In another study, wheeze in addition to bronchial hyperresponsiveness to nonspecific bronchial challenge was proposed as a means of identifying asthmatic children for epidemiological purposes [27]. However, although these two features are related, they do not necessarily coexist [22], and, in any case, widespread bronchial challenge testing would be impractical in general practice. The PPV of wheeze plus bronchial hyperreactivity versus physician diagnosis has been found to be only $74 \%$ (sensitivity $47 \%$ ) [22], less than that of any of the chosen scores used in the present study.

Whether using $>50 \%$ likelihood of asthma or meriting a trial of treatment to define possible asthma, all three sets of questionnaire score produced PPVs of $>78 \%$. Thus, comparatively few children would need to be invited for clinical assessment to detect a case of asthma. This would probably be acceptable in terms of practice workload and patient acceptance. The optimum balance between PPV, sensitivity and specificity appeared to be for the score of three or more positive responses plus a marker of severity. If this had been used to screen for individuals likely to have asthma (and so who needed clinical assessment), 270 children in the 1995 survey would have been identified, of whom 63 (3.5\% of all respondents) had no corroborative evidence of asthma diagnosis or asthma medication in their general practice records. A study of 12-14 yr-old children [6] in the UK found a similar rate of potential underdiagnosis $(1-3.4 \%)$.

The prevalence levels of probable asthma of $18.8 \%$ found in this study are in keeping with those of recent ISAAC surveys in England [6], although direct comparisons are not possible due to methodological differences between the studies.

\section{Conclusion}

When assessed against three standards derived from consensus expert opinion, a simple scoring system of three positive replies to key questions plus a marker of severity on a short postal questionnaire provided a good method of identifying children likely to have asthma, and so warranting clinical review.

Acknowledgements. The authors would like to thank the three consultant paediatricians J. Couriel, W. Lenny and A. Bradbury who produced our expert consensus diagnosis; the staff of Bowland Medical Practice, Tregenna Group Practice and the North West Lung Centre; and the parents/guardians who answered the questionnaires and who came for clinical review with their children. Finally, the authors thank all at the Royal College of General Practitioners (RCGP) Manchester Research Unit (now relocated to Aberdeen), without whose help and support this study could not have taken place. 
Appendix 1: Children's questionnaire

\section{CHILDREN'S QUESTIONNAIRE}

(To be completed by the parent or Guardian - Please tick the appropriate box) What is your child's date of birth?

1. Has your child had wheezing or whistling in the chest in the last 12 months?

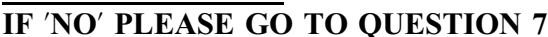

2. How many attacks of wheezing has your child had
in the last 12 months?
i) None
ii) 1 to 3
iii) 4 to 12
iv) More than 12

3. In the last 12 months, how often, on average, has your child's sleep been disturbed due to wheezing?
i) Never woken with wheezing
i) Less than one night per week
iii) One or two nights per week
iv) More than two nights per week

4. In the last 12 months, has wheezing ever been severe enough to limit your child's speech to only one or two words at a time between breaths?

5. Has your child been woken by an attack of wheezing in the last 12 months?

6. In the last 12 months, has your child's chest sounded wheezy during of after exercise?

7. In the last 12 months, has your child had a dry cough at night, apart from a cough associated with a cold or chest infection?

8.

Has your child had more than 3 courses of antibiotics

for respiratory infections (chest, ears or throat)

in the last 12 months?

9. Is your child currently taking any medicine (including inhalers, aerosols or tablets) for asthma?

10. Has your child had an attack of asthma in the last 12 months?

11. Has your child had hay fever or eczema?

12. Has anyone in your child's family (parents, grandparents, sisters or brothers) had asthma?

THANK YOU FOR YOUR HELP

$\begin{array}{llcl}\text { NO } & - & \text { YES } & - \\ \text { NO } & - & \text { YES } & - \\ \text { NO } & - & \text { YES } & - \\ & & & \\ \text { NO } & - & \text { YES } & - \\ & & & \\ \text { NO } & - & \text { YES } & - \\ \text { NO } & - & \text { YES } & - \\ \text { NO } & - & \text { YES } & - \\ \text { NO } & - & \text { YES } & - \\ \text { NO } & - & \text { YES } & -\end{array}$

PLEASE RETURN THIS FORM TO US IN THE ENCLOSED REPLY-PAID ENVELOPE

Appendix 2
INITIALS _-
COMPUTER NUMBER
DOB $1 /$
AGE
SEX M/F

\section{HISTORY}

1 Family history of atopic disease in first degree relatives. If Yes Specify

2 Atopic history of (hay fever/eczema) in the patient. If Yes Specify

3 Have your asthma symptoms been helped by asthma treatment given previously (Bronchodilators/Steroids)

$4 \quad$ Number of courses of antibiotics in the year (for chest, ENT complaints)

5 Wheeze/chest tightness on exposure to allergens (cat, dog, house dust mite, Grass pollen)

6a Wheeze/chest tightness waking the patient

b If yes is it $<1$ night/week ( ) 1-2 nights/week ( ) $>2$ nights/week ( )

7 Wheeze/chest tightness after exercise

8 Wheeze/chest tightness after exposure to non specific irritants (smoke, cold air)

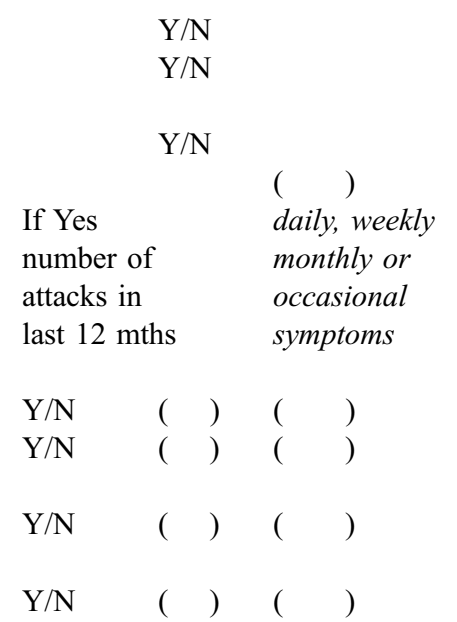


$9 \quad$ Has the wheezing ever been severe enough to limit speech to

1 or 2 words between breaths

10 Cough after exposure to allergens (cat, dog, HDM, grass pollen)

\begin{tabular}{|c|c|c|c|}
\hline $\mathrm{Y} / \mathrm{N}$ & ( & ) & \\
\hline $\mathrm{Y} / \mathrm{N}$ & ( & ) & \\
\hline $\mathrm{Y} / \mathrm{N}$ & ( & ) & \\
\hline $\mathrm{Y} / \mathrm{N}$ & ( & ) & \\
\hline $\mathrm{Y} / \mathrm{N}$ & ( & ) & \\
\hline $\mathrm{Y} / \mathrm{N}$ & ( & ) & \\
\hline $\mathrm{Y} / \mathrm{N}$ & ( & ) & \\
\hline $\mathrm{Y} / \mathrm{N}$ & ( & ) & \\
\hline $\mathrm{Y} / \mathrm{N}$ & ( & ) & \\
\hline $\mathrm{Y} / \mathrm{N}$ & ( & ) & \\
\hline $\mathrm{Y} / \mathrm{N}$ & ( & ) & \\
\hline $\mathrm{Y} / \mathrm{N}$ & ( & ) & \\
\hline
\end{tabular}

Night Cough (non productive) waking the patient

Cough after exercise

Have you had Wheezing/Whistling in your chest

Have you been breathless when the wheezing was present

Have you had wheezing/Whistling when you didn't have a cold

Have you been woken by an attack of breathlessness

Do you have Wheeze/chest tightness associated with seasonal change

Do you have Wheeze/chest tightness associated with colds

Cough after exposure to non specific irritants (smoke, cold air)

Have you been breathless without exercise

\section{EXAMINATION}

\begin{tabular}{llll}
\hline 26$)$ & a) Pulse & b) Blood Pressure \\
27) & Wheeze on examination & & Y/N
\end{tabular}

28) Chest Deformity Y/N If Yes, describe

29) PAST MEDICAL HISTORY Serious medical conditions that may cause respiratory symptoms

\section{0) DRUGS}

\section{SOCIAL HISTORY}

\begin{tabular}{|c|c|c|c|c|c|c|}
\hline 31) & Maternal Smoking & $\mathrm{Y} / \mathrm{N}$ & 32) If & yes number smoked/c & & $(\square)$ \\
\hline 33) & Paternal smoking & $\mathrm{Y} / \mathrm{N}$ & 34) If & yes number smoked/c & & $(\square)$ \\
\hline 35$)$ & \multicolumn{2}{|c|}{ Did the mother smoke in pregancy? } & $\mathrm{Y} / \mathrm{N}$ & & & \\
\hline 36) & \multicolumn{2}{|c|}{ If yes number smoked/day } & ( & 2nd trimester $(\square)$ & & rimester $(\square)$ \\
\hline 37) & Does the child smok & $\mathrm{Y} / \mathrm{N}$ & 38) If & yes number smoked/ & day & \\
\hline
\end{tabular}

39) Days missed off school in last 12 months with respiratory complaints (

\section{TESTS}

21) WEIGHT _ $\mathrm{kg}$

22) HEIGHT $\mathrm{cm}$

23) $>15 \%$ reversibility FEV1 with bronchodilator $\quad \mathrm{Y} / \mathrm{N} \quad($ )\%

24) $\mathrm{FEV} 1 / \mathrm{VC} \quad$ Best of three acceptable blows

25) Peak Flow Diaries (Raw data presented to experts with this proforma)

26) Positive Exercise Test Y/N

POST EXERCISE VALUES

\begin{tabular}{|l|l|l|l|l|l|l|l|l|}
\hline & Best Pre-test FEV1 & 2 mins & 3 mins & 5 mins & 10 mins & 15 mins & 20 mins & Final value \\
\hline FEV1 & & & & & & & & \\
\hline
\end{tabular}

Positive skin tests to

Histamine
-ve control
House dust mite
Cat
Grass
Cockroach
Dog

On the basis of this information, do you think that this patient has (please tick your choice):-

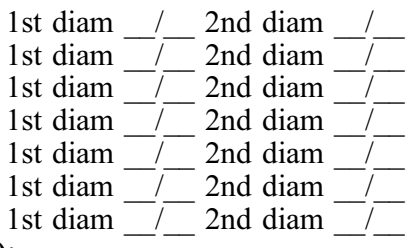

\begin{tabular}{|l|l|}
\hline$>90 \%$ chance of having asthma & \\
\hline $50-90 \%$ chance of having asthma & \\
\hline $10-50 \%$ chance of having asthma & \\
\hline$<10 \%$ chance of having asthma & \\
\hline
\end{tabular}


Appendix 3: Estimation of sensitivity, specificity, prevalence and predictive value from a stratified random sample

The method is illustrated for the situation in which three or more positive responses is considered as a positive screening test and a positive diagnosis is " $>50 \%$ likelihood of asthma"; it is easily generalized to other scenarios.

Let wi denote the number of children in stratum $i$ of the survey sample ( $\mathrm{i}=1,2,3,4$ and 5). For those who were examined clinically, let pi be the proportion in stratum i who had a positive diagnosis. Then

$$
\begin{gathered}
\text { PPV }=\sum_{i=3}^{i=5}(w i \times p i) / \sum_{i=3}^{i=5} w i \\
\text { Sensitivity }=\sum_{i=3}^{i=5}(w i \times p i) / \sum_{i=1}^{i=5} w i \times p i \\
\text { Specificity }=\sum_{i=1}^{i=2}(w i \times(1-p i)) / \sum_{i=1}^{i=5} w i \\
\text { Prevalence }=\sum_{i=1}^{i=5}(w i \times p i) / \sum_{i=1}^{i=5} w i
\end{gathered}
$$

\section{References}

1. de Marco R, Cerveri I, Bugiani M, Ferrari M, Verlato G. An undetected burden of asthma in Italy: The relationship between clinical and epidemiological diagnosis of asthma. Eur Respir J 1998; 11: 599-605.

2. Jones K. Asthma - still a challenge for general practice. $J$ $R$ Coll Gen Pract 1989; 39: 254-256.

3. Jones K, Lane D, Holgate ST, Price J. Asthma: a diagnostic and therapeutic challenge. Fam Pract 1991; 8: 97-99.

4. Warner JO. Asthma: a follow up statement from an international paediatric asthma consensus group. Arch Dis Child 1992; 67: 240-248.

5. Charlton I, Jones K, Bain J. Delay in diagnosis of childhood asthma and its influence on respiratory consultation rates. Arch Dis Child 1991; 66: 633-635.

6. Kaur B, Anderson HR, Austin J, et al. Prevalence of asthma symptoms, diagnosis, and treatment in $12-14 \mathrm{yr}$ old children across Great Britain (international study of asthma and allergies in childhood, ISAAC UK). BMJ 1998; 316: 118-124.

7. Siersted HC, Boldsen J, Hansen HS, Mostgaard G, Hyldebrandt N. Population based study of risk factors for underdiagnosis of asthma in adolescence: Odense schoolchild study. BMJ 1998; 316: 651-656.

8. Agertoft L, Pedersen S. Effects of long-term treatment with an inhaled corticosteroid on growth and pulmonary function in asthmatic children. Respir Med 1994; 88: 373-381

9. Pederson S. Early use of inhaled steroids in children with asthma. Clin Exp Allergy 1997; 27: 995-999.
10. Boner AL, Piacentini GL, Bonizzato C, Dattoli V, Sette L. Effect of inhaled beclomethasone diproprionate on bronchial hyperreactivity in asthmatic children during maximal allergen exposure. Paediatr Pulmonol 1991; 10: 2-5.

11. Frank PI, Ferry S, Hannaford P. The use of a postal questionnaire to estimate the likely underdiagnosis of asthma in children living in South Manchester, UK. Eur Respir J 1995; 8: Suppl. 19, 284s.

12. Keil U, Wieland S. International Asthma and Allergy Study. Lancet 1992; 340: 46.

13. Neville RG, Bryce FP, Robertson FM, Crombie IK, Clarke RA. Diagnosis and treatment of asthma in children: Usefulness of a review of medical records. $\mathrm{Br} J \mathrm{Gen}$ Pract 1992; 42: 501-503.

14. Pill J. The Delphi Method: Substance, Context, A Critique and an Annotated Bibliography. Socio-Econ Plan Sci 1971; 5: 57-59.

15. ATS Statement Snowbird Workshop on standardization of spirometry. Am Rev Respir Dis 1979; 119: 831-838.

16. American Thoracic Society. Standards for the diagnosis and care of patients with chronic obstructive pulmonary disease (COPD) and asthma. Am Rev Respir Dis 1987; 136: 225-244.

17. Custovic A, Arifhodzic N, Robinson A, Woodcock A. Exercise testing revisited:The response to exercise in normal and atopic children. Chest 1994; 105: 1127-1132.

18. Basomba A, Sastre A, Peleaz A, Romar A, Campos A, Garcia-Villalmanzo A. Standardisation of the prick test. Allergy 1985; 40: 395-399.

19. Stata Corp. Stata Statistical Software: Release 5.0. College station TX, Stata Corporation, 1997.

20. Efron B, Tibshirani RJ. An Introduction to the bootstrap. Chapman and Hall, New York. 1993.

21. Frank PI, Ferry S, Moorhead T, Hannaford P. Use of a postal questionnaire to estimate the likely under-diagnosis of asthma-like illness in adults. Br J Gen Pract 1996; 46: 295-297.

22. Jenkins MA, Clarke JR, Carlin JB, et al. Validation of questionnaire and bronchial hyperresponsiveness against respiratory physician assessment in the diagnosis of asthma. Int J Epidemiol 1996; 25: 609-616.

23. Burr ML. Diagnosing asthma by questionnaire in epidemiological surveys. Clin Exp Allergy Editorial 1992; 22: 509-510.

24. Konig P. Hidden asthma in childhood. Am J Dis Child 1981; 135: 1053-1055.

25. Cloutier MM, Loughlin GM. Chronic cough in childrena manifestation of airway hyperreactivity. Paediatrics 1981; 67: 6-12.

26. Kelly YJ, Brabin BJ, Milligan PJ, Reid JA, Heaf D, Pearson MG. Clinical significance of cough and wheeze in the diagnosis of asthma. Arch Dis Child 1996; 75: 489493.

27. Toelle BG, Peat JK, Salome CM, Mellis CM, Woolcock AJ. Toward a definition of asthma for epidemiology. Am Rev Respir Dis 1992; 146: 633-637. 